\title{
Do relatório ao relato, da alienação ao sujeito: a experiência de uma prática clínica com refugiados em uma instituição de saúde
}

\author{
Marie-C. Saglio-Yatzimirsky* \\ Instituto de Línguas e Civilizações Orientais (INALCO). Paris, França; \\ Hospital Avicenne. Paris, França
}

Resumo: Neste artigo, buscaremos evidenciar a especificidade e os limites de uma consulta transcultural no Serviço de Psiquiatria do Hospital Avicenne (França) com sujeitos requerentes de refúgio, originários principalmente da África e Ásia do Sul, atendidos por distúrbios psicotraumáticos. Tratar-se-á de tentar mostrar que uma abordagem clínica, que leve em conta o contexto sociopolítico e a situação jurídica desses pacientes "migrantes", irá possibilitar a emergência da palavra do sujeito. A partir da construção de dois fragmentos de caso, mostraremos como as representações político-sociais acerca do "migrante", "refugiado", "vítima", "suspeito", deixam suas marcas concretas e simbólicas nos sujeitos bem como influenciam os modos de condução do trabalho clínico. Isso nos permitirá, em um segundo momento, questionar a noção de alienação. Por fim, iremos lançar uma proposição clínica que tem a finalidade de esvaziar o espaço da consulta em psicoterapia das amarras impostas pelas representações sociais que calam o sujeito.

Palavras-chave: requerentes de asilo, sujeito, alienação, trauma, cultura.

\section{Introdução}

Em um dia qualquer, em uma sala de audiência da Corte Nacional de Direito de Asilo (CNDA), enquanto o tempo reservado para a entrevista com o juiz se esvaía - e com isso toda a esperança de obtenção de recurso para sua solicitação de asilo -, Karan emudece. De origem tâmil do Sri Lanka, chegou à França há aproximadamente um ano, e nos conta que ele e sua família viveram os horrores de uma guerra sem fim, além disso, foi preso e torturado. Seu irmão foi sequestrado, e Karan sabe - em uma espécie de intuição que só aqueles que viram a morte de frente são capazes de sentir - que seu irmão é hoje um cadáver, que será encontrado mais dia, menos dia, "inchado como um peixe morto, boiando num riacho". Semprún (1994), sobre sua experiência nos campos, escreveu: "a morte não é algo de que tenhamos nos aproximado, esbarrado, e da qual tenhamos conseguido escapar...A morte, nós a vivemos". E esta experiência da morte não é "crível", nem algo que possamos compartilhar, nem "compreensível" (p. 121).

Karan, diante do juiz, emudece. É incapaz de responder quando questionado. Seu amigo deixa a sala de audiência, para não assistir ao insuportável "desperdício" (waste) de um homem que assina sua condenação. "Por que você se recusa a cooperar?", repete o juiz. No entanto, Karan já habita outra dimensão daquela imposta pelo procedimento administrativo. $\mathrm{O}$ dispositivo jurídico, feito de perguntas e respostas, acaba por reativar as feridas deixadas pela tortura dos interrogatórios vividos por ele na prisão. Com seu silêncio Karan recusa cooperar? Seu silêncio é uma recusa a quê, exatamente? Ao processo e ao sistema jurídico como um todo? A menos que possamos pensar em

* Autora correspondente: marieyat@hotmail.com seu silêncio como a expressão de um mecanismo de defesa contra o retorno da angústia, um modo de "defesa" último contra sua "aniquilação" como sujeito?

Ao chegar ao serviço de psicotraumatologia do Hospital Avicenne, depois da primeira entrevista, e de volta à realidade brutal do fracasso do seu pedido de recurso, Karan começa a se interrogar sobre seu silêncio. Ele nos diz quão insuportável é portar a marca do "estrangeiro, tâmil do Sri Lanka, refugiado, migrante, traumatizado". A partir do encontro transferencial, ele será capaz de pensar sua recusa de resposta como uma escolha. Alienação ou sujeito responsável? Diremos se tratar, nesse momento, de pura recusa alienante. $\mathrm{O}$ que se visa na alienação não é apenas destituir o sujeito de si mesmo graças a um processo de categorização e identificação pelo pior, mas também de "destituir o sujeito do mundo", como nos dizem Deleuze e Guattari (1980).

Neste artigo buscaremos evidenciar a especificidade e os limites de uma consulta hospitalar com sujeitos refugiados, atendidos por distúrbios psicotraumáticos. Trauma e cultura estão no cerne deste trabalho psicoterápico. Nossos atendimentos são atravessados pela singularidade da situação sociopolítica desses pacientes, mas ainda pela estrutura administrativa impregnada de certa representação do sujeito requerente de refúgio, tributária de uma concepção ocidental de ajuda médica e psíquica destinada a tratar a desorientação do sujeito migrante. Essas inúmeras concepções aprisionam o sujeito e o alienam, tornando imprescindível que sejam capazes de criar laços e estratégias de cooperação que o acompanhem em todo processo

\footnotetext{
1 Aqui, tomamos de empréstimo o subtítulo da obra de Devereux La renonciation à l'identité, défense contre l'anéantissement (2009). [A renúncia da identidade. Defesa contra a aniquilação].
} 
administrativo para obtenção de documentos e de proteção legal. No entanto, o que evidenciamos é que a voz dos sujeitos tende a extraviar-se, a perder-se no decorrer deste longo percurso. Deste modo, podemos nos questionar quanto aos limites da consulta psicoterápica: de que liberdade dispomos em face das exigências do trâmite administrativo? De qual sujeito tratamos?

Tratar-se-á neste artigo, menos de desconstruir as proposições e práticas de uma clínica transcultural com refugiados, do que de tentar mostrar que uma abordagem clínica que leve em conta o contexto sociopolítico e a situação jurídica desses pacientes "migrantes requerentes de refúgio" irão possibilitar a emergência da palavra do sujeito e uma melhor apreensão de sua subjetividade. Inicialmente, iremos descrever a estrutura das consultas de psicotraumatologia transcultural com os "requerentes de refúgio" em sua especificidade de criar um espaço-tempo definido pelo contexto político e a urgência. A partir da construção de dois fragmentos de caso, mostraremos como as representações político-sociais acerca do "migrante", "refugiado", "vítima", "suspeito" deixam suas marcas concretas e simbólicas nos sujeitos e influenciam os modos de condução do trabalho clínico. Isto nos permitirá, em um segundo momento, questionar a noção de alienação, acerca da identidade cultural e política relacionada ao lugar social destinado ao refugiado. Por fim, iremos lançar uma proposição clínica que tem o objetivo de esvaziar o espaço da consulta em psicoterapia das amarras impostas pelas representações sociais que calam e alienam o sujeito em sua demanda por refúgio.

\section{Da oferta e da demanda: entre as exigências institucionais e a dinâmica clínica}

\section{O contexto do atendimento}

Concentrar-se na questão dos refugiados, mais precisamente, no caso dos requerentes de refúgio é o objetivo deste artigo. Esta distinção é importante, pois o requerente encontra-se ainda em uma zona indefinida, sem garantias legais de permanência no novo território. Nestes casos, sua palavra é considerada suspeita até a obtenção de seus documentos oficiais. Na França, o asilo constitucional é dado "a toda pessoa perseguida (em seu país) em razão de sua ação em prol da liberdade". Uma proteção acessória é dada a toda pessoa que "provar que é exposta, no seu país, a uma das ameaças, a seguir: à pena de morte, à tortura ou a penas de tratamento desumano ou degradante; tratando-se de um cidadão civil, uma ameaça grave, direta e individual contra sua vida ou sua pessoa em razão de uma violência generalizada resultante de uma situação de conflito armado ou internacional".

Na maioria das vezes, são estes os sujeitos que recebemos no Serviço de Psiquiatria do Hospital Avicenne: vítimas de guerra, de tortura, de estupro. Esses sujeitos nos são encaminhados pelos abrigos que os acolhem enquanto dão início ao procedimento para legalização de sua documentação e moradia ${ }^{2}$. Inicialmente o requerente elabora um dossiê que será examinado em primeira instância pela OFPRA (Oficio Francês de Proteção aos Refugiados e Apátridas) que aceita apenas 10\% dos dossiês (em 2012, apenas 9,4\%). Ou seja, apenas uma pequena minoria terá direito à moradia e ao trabalho. Após a recusa de seu pedido de asilo pela OFPRA, o requerente poderá ainda contestar essa decisão administrativa. Neste caso, os sujeitos deverão se dirigir à Corte Nacional do Direito de Asilo (CNDA). Se obtêm outra recusa nesta instância, poderão dessa vez incluir novos elementos ao antigo dossiê e pedir à OFPRA que se pronuncie novamente. Em 2012, 21,6\% das requisições foram deferidas. Nesse período, um total de 41.254 primeiros pedidos foram aceitos na França. Os principais países de origem dos pedidos de asilo foram: $10 \%$ do Congo, $10 \%$ da Rússia, $6 \%$ do Sri Lanka, $5 \%$ do Kosovo, $5 \%$ da China, 4,5\% do Paquistão, da Turquia e Geórgia. O número pequeno de legalizações na França explica-se por uma política de cotas restritas, tributária da institucionalização da política migratória europeia fixada na Convenção de Dublin II.

Obter o estatuto de refugiado garante ao sujeito um alívio material, social e psíquico, pois poderá buscar moradia, formação para entrar no mercado de trabalho, recorrer ao sistema de saúde e preparar a vinda de sua família via pedido de "união familiar". Além desses inúmeros aspectos da vida prática, do ponto de vista psicológico, obter o estatuto de refugiado significa o reconhecimento de sua história vivida e narrada. No entanto, esse reconhecimento pode implicar uma identificação do sujeito ao lugar de "vítima", daquele que teve que buscar proteção, o que não é sem consequências para a subjetivação. Por outro lado, não obter a documentação significa viver ilegalmente na França e ter de enfrentar as consequências dessa difícil escolha. Para esses sujeitos, muitas vezes perseguidos no seu país de origem, esta posição de ilegalidade pode contribuir para a manutenção dos pacientes no tempo do trauma. $\mathrm{Na}$ clínica vemos como o trauma é reativado e pode fazer irrupção sob a forma de uma crise de angústia quando o sujeito é confrontado com a polícia francesa em um controle de identidade, por exemplo, ou mesmo em um simples controle do ticket de transporte.

Algumas migrações forçadas serão vividas como trauma extremo, uma vez que os acontecimentos que levam o sujeito a migrar são sempre impregnados de horror: a morte violenta dos familiares, o abuso, a perda simbólica da terra etc. A violência dos acontecimentos está na origem

\footnotetext{
2 A admissão do benefício de proteção subsidiária tem uma duração temporária de um ano, podendo ser renovada, dá direito em princípio a um visto de permanência temporário, com a menção "vida privada e de família”, que é dado também ao cônjuge do requerente e a seus filhos menores. Este visto de permanência permite o trabalho e o exercício de uma atividade profissional. No nível europeu, a Convenção de Dublin (assinada em 1990, efetivada em 1997, e adotada em 2003 na Dublin II) e o Tratado de Amsterdã (1999) organizam a questão do asilo na comunidade europeia. Uma das cláusulas mais importantes destas convenções é a determinação do Estado responsável de uma demanda de asilo.
} 
do trauma da partida e impede o sujeito de se relacionar no país de destino: o sujeito deixa de poder viver. Estabelece-se o que em uma clínica do sintoma se definiria como Síndrome do Estresse Pós-traumático. Esses pacientes chegam ao atendimento com os sintomas de impossibilidade de dormir, têm pesadelos, reminiscências, sofrem de dissociação traumática e isolamento. Em geral são indivíduos sozinhos que não possuem uma rede familiar na França. Como migrantes que solicitam refúgio, são encaminhados para os Centros de Acolhida dos Requerentes de Asilo $(\mathrm{CADA})^{3}$, quando ainda restam vagas disponíveis, senão tentarão viver nas ruas, nos abrigos de urgência ou serão acolhidos temporariamente por alguém de sua comunidade de origem. Eles serão encaminhados ao serviço médico psiquiátrico apenas quando a manifestação de seu sofrimento psíquico se torna evidente. A França possui alguns serviços hospitalares dedicados ao tratamento psicológico e psiquiátrico do sofrimento do sujeito migrante, um deles é localizado dentro do Hospital Avicenne.

O Hospital Avicenne, situado em Bobigny, Seine-Saint-Denis, é um hospital do serviço público de saúde francês. Foi inaugurado em 1935 como o Hospital Franco-muçulmano de Paris. Inicialmente foi concebido para receber a população muçulmana de Paris, principalmente de origem argelina e marroquina, no contexto da colonização. Uma parte dos funcionários recebeu formação em língua árabe. O fim da colonização marcou o fim dessa especialização no atendimento. No entanto, com a setorização do acesso ao sistema hospitalar, Avicenne passou a acolher, majoritariamente, a população do norte da região parisiense (setor sanitário 4 Paris-Norte). Este setor é o mais pauperizado da região, constituindo-se em uma área de forte mistura cultural e concentrando grande parte da comunidade africana e asiática da região. Por fim, o Hospital Avicenne encontra-se localizado próximo ao aeroporto Roissy Charles de Gaulle, porta de entrada dos refugiados e migrantes.

Foi nesse hospital que Tobie Nathan criou em 1979 a primeira consulta etnopsiquiátrica no Serviço de Psiquiatria de Serge Lebovici. Posteriormente, essas consultas ficaram a cargo de Marie Rose Moro que manteve a proposta de atendimento psiquiátrico, mas que também incluiu uma nova proposição de consultas de abordagem etnopsicanalítica.

\section{Clínica do trauma ${ }^{4}$, clínica da cultura}

Neste ambiente, com forte legado da tradição psiquiátrica, alguns dispositivos clínicos destinados às populações migrantes puderam ser criados, dentre eles, atendimento em psicotraumatologia em que são acolhidos

3 Centre d'Accueil de Demandeurs d'Asile (CADA) é um abrigo ou dispositivo de hotel especializado na acolhida dos requerentes de asilo durante o processo de exame de seu pedido, financiado pelo Estado.

4 A partir de Bokanowski (2002), devemos separar o trauma "figurado", ou seja, o acontecimento traumático, do trauma em si que designa a ação do acontecimento sobre o psiquismo e que supõe sua efração. os sujeitos que viveram situações de trauma extremo. $\mathrm{Na}$ prática, os pacientes são encaminhados pelos abrigos da região, em particular, pelos assistentes sociais ou pelos médicos que trabalham em rede com os Centros de Acolhida dos Requerentes de Asilo e com a Ajuda Social à Infância (ASE), que acolhem ou recebem esses sujeitos. Eles podem ainda ser encaminhados por compatriotas que conhecem, ou são eles próprios pacientes do serviço de psicotraumatismo de Avicenne. Diremos que no primeiro contato com o paciente se tentará vislumbrar a presença dos sintomas da Síndrome de Estresse Pós-traumático.

Do ponto de vista clínico, isso significa dizer que $o$ atendimento trará, em seu cerne, a problemática do trauma e da cultura. Ao falarmos de trauma, devemos traçar a diferença entre trauma intencional, engendrado por uma série de situações políticas diversas, um trauma "feito por outros homens", do trauma não intencional, relacionado a uma catástrofe natural ou a um acidente. Nossa prática clínica nos confronta com pacientes migrantes que viveram situações de violência extrema em um contexto de guerras étnicas, sectárias ou religiosas, originários majoritariamente, da África subsaariana ou da Ásia. O trauma advém da ruptura dos códigos de transmissão geracional e sexual da sociedade de origem (incestos e estupros intrafamiliar, massacre de familiares, fuga da casa parental, não proteção dos filhos mais velhos etc.). O trauma "intencional" se caracteriza pela inversão ou pela destruição das invariantes antropológicas e das regras de organização familiar e social da cultura de origem, imposto por outrem. Quando a cultura perde seus "lugares de palavra" (Cyrulnik, 2012, p. 278).

A este trauma intencional, outro trauma se sobrepõe ao destino do sujeito: o da migração e sua desestabilização dos lugares de sentido e de cultura, o que reforça seu sentimento de perda real e simbólica. Por outro lado, a distinção entre migração buscada e migração forçada pela "violência e pela miséria" é fundamental, pois é neste ponto que "a dimensão da perda e a dificuldade de se localizar no mundo tomam um lugar primordial" (Rosa, 2012). A qualificação "intencional", ou segundo Sironi (1999) política do trauma, é fundamental, pois permite, por um lado, nos aproximarmos da experiência psíquica do paciente em face do irrepresentável e, por outro lado, levamos em conta $\mathrm{o}$ aspecto cultural do paciente. Este irá funcionar como um anteparo protetor, permitindo ao sujeito extrair um sentido de sua expressão de sofrimento.

Este primeiro postulado de um "trauma intencional" relaciona-se à ideia de que face a face com a morte, o sujeito é confrontado com a experiência do mal pelo ato de destruição de sua cultura por outrem. Nossa hipótese é que esses sujeitos experimentam, em um determinado momento de sua maturação identitária e social, a presença do mal presente no outro, seu semelhante, o que acaba lhes confrontando com a estranha experiência do mal em si mesmo. Esta experiência reveste a própria representação que o sujeito porta sobre si mesmo e sobre o outro. Como nos diz Semprún (1994), "é claro que o Mal não é inumano, ou então é aquilo que há de inumano no homem. ... O 
inumano do homem enquanto possibilidade vital, enquanto projeto pessoal...enquanto liberdade" (p. 120). Este mal que por vezes é experimentado pelo sujeito como algo que lhe chega do exterior, mas também como algo que lhe anima do interior, como expressão de um projeto pessoal, carrega a dupla natureza do trauma: externa como experiência do carrasco, e também interna, como inerente ao próprio psiquismo. Assim, essa experiência do mal, por meio da inversão dos referentes culturais e da relação do sujeito ao outro, nos parece ser particularmente pensada não como um continuum da pulsão de morte, mas sim em seu caráter específico (Mijolla-Mellor, 2011; Zaltzman, 1999, 2007). Temos acesso às consequências dessa relação específica com a alteridade na relação transferencial e contratransferencial que fundamentam a experiência psicoterápica com os sujeitos que atendemos. Voltemos à construção do enquadramento psicoterápico.

\section{Demanda institucional e demanda clínica}

A complexidade do conceito de "demanda", sua face institucional e clínica, deve ser levada em conta no atendimento do sujeito migrante requerente de refúgio, uma vez que a situação política e o pertencimento cultural do paciente podem sobredeterminá-la ou fazer que os aspectos clínicos e institucionais entrem em contradição. Voltemos ao enquadre concreto do atendimento clínico. É raro que a demanda seja enunciada pelo próprio paciente: aquele que solicita refúgio é geralmente levado ao atendimento por um terceiro que o orienta. Este encaminhamento é uma espécie de mediação da demanda do paciente. Afinal, de que demanda se trata?

Devemos distinguir, inicialmente, uma demanda de atendimento em psicoterapia de uma demanda de "ajuda" mais vaga e menos elaborada. Em geral, os pacientes migrantes, requerentes de asilo, conhecem a psiquiatria como uma proposta médica ocidental que conjugam lado a lado às outras formas de cuidado e de tratamento tradicionais. O psicólogo, o psicanalista ou o psicoterapeuta são, no imaginário desses pacientes, personagens raros ou inexistentes, sempre atrelados à ideia de uma medicina destinada às elites.

Basicamente, os sujeitos migrantes buscam o serviço de psiquiatria, apenas quando se encontram em um estado de sofrimento psíquico intenso. Seus sintomas lhes confrontam a uma insuportável experiência de estranhamento de si mesmos: pesadelos, dissociação traumática, perda de concentração e de memória, estados depressivos que lhes preocupam. Sua queixa aparece sob a forma "tenho medo de estar enlouquecendo". Ultrapassar o estigma da busca por um serviço de psiquiatria, "para loucos", é prova de muita coragem. Eles buscam ser tratados, esperam encontrar um médico psiquiatra e se surpreendem ao encontrarem um serviço de atendimento em psicoterapia, construído em torno da palavra e não ancorado na medicalização do sofrimento psíquico.

Uma vez que a demanda de tratamento psíquico pode ser claramente formulada, os pacientes começam a fazer progressivamente a diferença entre hospital biomédico e os outros tipos de atendimentos psicoterápicos. Alguns desses pacientes irão justificar seu sofrimento por serem vítimas de uma maldição, nestes casos irão buscar, em paralelo ao atendimento clínico, a ajuda de um curandeiro. Por isso, o serviço médico do Avicenne é percebido pelos pacientes migrantes diferentemente dos outros hospitais de saúde mental: "eu busquei o hospital, pois me disseram que aqui podemos falar de todo tipo de coisa, por exemplo, eu não poderia falar dos djinns (espíritos) no meu centro de saúde", nos diz um paciente que recebe acompanhamento de um Centro Médico Psicológico (CMP) do setor. O importante é que as diferentes representações que dominam as diversas formas de prática da Medicina Ocidental e das práticas tradicionais não são tomadas como contraditórias pelo serviço transcultural do Avicenne.

Enfim, outro aspecto que entra na cena clínica e intervém na demanda do paciente é a urgência política e administrativa que atravessa o percurso do sujeito requerente de asilo. O certificado de atendimento psicoterápico é um documento de que necessita o requerente de asilo para apoiar seu dossiê à OFPRA (ou à CNDA no caso de um recurso). A demanda do sujeito que nos chega para atendimento é diretamente "interessada", uma vez que o psicólogo é colocado, pelo sistema jurídico-administrativo, na posição de um expert (Fassin \& Rechtman, 2007). É o terapeuta que deverá atestar a existência de uma síndrome pós-traumática e sua compatibilidade com os acontecimentos que o sujeito diz ter vivido em seu país. Esse é o lugar também ocupado pelo médico que atesta as marcas de tortura física e que fornece ao sujeito um certificado que lhe permitirá a obtenção do "direito de permanência para tratamento" (Ticktin, 2013).

Vemos então como o pedido do sujeito é atravessado por inúmeras mediações vindas dos diversos atores da instituição jurídica, social e médica. Esse pedido é acompanhado por outra forma de demanda, a demanda clínica do sujeito: o reconhecimento do sofrimento psíquico, a localização do conflito, a aliança terapêutica. É provável que na clínica do trauma com os requerentes de asilo a distinção entre a noção de demanda "recoberta" ou "emergente" não seja tão pertinente. $\mathrm{O}$ psiquismo do sujeito marcado pela violência é atravessado pelo trauma. Diremos não haver mais distância entre o acontecimento traumático e sua história, e nesta brecha espaço-temporal, o sujeito termina por se exilar do laço social. Confrontado à emergência da angústia, o sujeito acaba silenciando perante o signo da morte e entra em um estado de depressão melancólica, que convencionamos chamar de gozo do trauma. Uma espécie de retorno ao narcisismo primário impede o sujeito de se lançar rumo ao exterior, em uma relação de objeto, o que dificulta a construção da demanda. Pensamos que a particularidade de uma clínica do trauma é de não estar condicionada a uma demanda inicial, mas de nascer da instalação de uma relação contratransferencial. Como nos diz Ferenczi (1982), no trauma o sujeito perde os laços identificatórios com o semelhante, "esta paralisia transforma 
brutalmente a relação de objeto, que advém impossível, em uma relação narcísica" (p. 48). Os pacientes que chegam ao serviço assistencial do hospital carregam esse paradoxo: eles nos pedem ajuda, mesmo quando vivem o trauma como algo intransponível. Nossa função clínica é a de possibilitar a emergência de uma nova relação de objeto, fundamental à reconstrução da alteridade, a partir de um desejo do sujeito de reencontro com o outro. Será apenas nessas condições que pode emergir uma demanda, nos termos psicanalíticos.

\section{"A retórica da urgência"}

$\mathrm{O}$ atendimento psicoterápico - individual ou em grupo - se realiza em uma temporalidade particular. Primeiramente temos a especificidade da duração do tratamento, quase sempre tributário da situação administrativa do requerente de asilo. Em regra geral, o atendimento termina quando os pacientes recebem seus documentos, etapa administrativa que transforma radicalmente sua condição material e psíquica.

A situação sociopolítica tem um impacto direto sobre a dinâmica da consulta. A perspectiva das entrevistas à OFPRA ou à CNDA comanda o ritmo das consultas e, ainda mais importante, ditam parte do conteúdo discursivo das consultas, por exemplo, o caso de um casal de Bangladesh que fugiu do país após serem torturados e presos. Acolhemos Aziz e sua esposa, separadamente, durante 6 meses em nosso atendimento de psicotrauma, logo após chegarem à França. O casal apresentava fortes sintomas pós-traumáticos: depressão, isolamento relacional importante, pesadelos, ansiedade, medo. O começo da reconstrução do casal se deu a partir de um projeto de parentalidade. As consultas começam a se espaçar. A convocação que recebem para uma entrevista da OFPRA chega para mudar o ritmo do trabalho psicoterápico, impondo um calendário de atendimentos regulares, a fim de preparar os pacientes para a entrevista. Paradoxalmente, isso acaba mergulhando-os em uma espécie de atualização dos acontecimentos políticos de seu país, fazendo emergir as feridas do trauma, em um momento em que ainda não estavam prontos psiquicamente para lidar com essa nova confrontação. Diante da aproximação da data de sua entrevista, Aziz irá reforçar os elementos de seu dossiê: ele dirá o impensável, aquilo que mesmo sua mulher ignora, a saber, o abuso sexual do qual foi vítima na prisão de Bangladesh. O estupro constituiu uma violência radical a sua integridade. Ao integrar esse fato em seu dossiê, ele aceita o risco de devastação subjetiva ao ser interrogado pela administração da OFPRA.

Um termo se impõe para descrevermos o ritmo de nossas consultas: urgência. Urgência de tratamento que supõe uma intervenção imediata, sob pena de agravar a situação psíquica do paciente. Ora, esta noção de urgência é problemática quando se trata da situação psicoterápica, em que é precisamente a construção de um trabalho ancorado em uma temporalidade que pode inverter a dinâmica da ruptura traumática, de sua repetição e sua regressão. No caso da clínica com requerentes de asilo, várias temporalidades parecem se misturar e, algumas vezes, se contrapor: o ritmo da consulta articulado à trajetória do requerente de asilo e seu processo jurídico-administrativo, o tempo do diagnóstico que identifica os riscos de dessubjetivação, ou de passagem ao ato, que pode exigir uma saída pontual via medicação, e por fim, o tempo da escuta clínica, de uma psicoterapia que se inscreve em outra duração. Este último repousa sobre a existência de inúmeros tempos psíquicos e sobre a atemporalidade do inconsciente: o tempo paralisado da dessubjetivação traumática, que destrói o passado e o futuro do paciente, o tempo suspenso da repetição mortífera, que ejeta o sujeito do laço, o progressivo tempo de uma reconstrução psíquica articulada à temporalidade de uma verdade histórica.

O tempo da urgência é contrário ao tempo necessário para uma clínica analítica que visa organizar os acontecimentos vividos pelo sujeito em uma narrativa diacrônica. O relato não é afeito ao tempo linear, mas a uma narratividade que permite atribuir ao sujeito um lugar entre um passado e um futuro, como aponta Hassoun (1994) ao identificar a necessidade de uma "palavra que dialetiza". De acordo com Ricoeur (1990), esse tempo permitiria a emergência de um sujeito com um relato coerente, enlaçado em uma "identidade narrativa", na "maneira de se contar a si mesmo e aos outros e de se reconhecer no seu relato" (Hochman, 2001, p. 32). Ora, esse tempo da narratividade é abalado pela "retórica da urgência" (Ticktin, 2013), e essa "palavra que dialetiza" é abafada pelas injunções políticas: "Por que você se recusa a cooperar?" Diante dessa retórica da urgência, só resta a Karan emudecer.

Essa retórica da urgência é denunciada por Ticktin (2013), sobretudo quando se trata dos dispositivos de atendimento humanitário, também nos parece válida para pensarmos na clínica com refugiados. Trata-se da exigência de uma resposta rápida que permite o "caring” (cuidado), mas não um trabalho a longo prazo de "curing" (cura). Diremos que essa modalidade de reação na urgência, em face da demanda do refugiado, serve aos interesses políticos de um sistema jurídico-administrativo excludente (lembremos que apenas $20 \%$ irão obter o direito à moradia). Esta retórica da urgência, em nome de um imperativo moral, legitima, segundo Ticktin (2013), as falhas do sistema político.

\section{A política da alienação}

O lugar social destinado a Karan como migrante requerente de asilo parte da alienação do sujeito, o que em termos psicanalíticos implica dizer que o sujeito se aliena do mundo da significação, da dimensão do desejo e da alteridade. No caso do sujeito migrante, este Outro é incorporado pelo contexto de acolhida em território francês, que lhe impõe certo número de normas que podem acabar ameaçando a ordem simbólica e cultural que atribui o lugar dos sujeitos no mundo. Essa alienação política não é sem efeito sobre os sujeitos, e podemos vislumbrar sua 
incidência na cena clínica pelos modos de aprisionamento que engendram: identificação da figura social do imigrante, do refugiado, da vítima ou do suspeito.

\section{Exterritorialização ou migração?}

Como dissemos, no caso dos refugiados vítimas de violências, a migração é pensada como potencialmente traumática. Não se trata de um deslocamento planejado, elaborado, compartilhado com o grupo de origem (Rousseau, Taher, Gagné, \& Bibeau, 1998), nem tampouco de um desejo de partida próprio ao tempo da adolescência (Vacchiano, 2013). Quando os requerentes de asilo chegam para serem atendidos no serviço clínico, é raro que a migração seja percebida como uma sorte ou oportunidade. Menos ainda, é raro que a migração possa ser pensada em termos de integração e de aculturação. A migração é vivida como fuga, quase sempre tem destino incerto. Alguns de nossos pacientes nos dizem que nada sabiam sobre o rumo que iriam tomar ao embarcarem junto com os "atravessadores". Eles chegam à França sem terem escolhido, afirmam que as condições de espera em território francês são melhores do que em outros países europeus, onde a possibilidade de conseguirem seu estatuto é ainda mais precária.

Aziz, 28 anos, um jovem de Bangladesh, nos chega para a consulta por causa de sua esposa. Ele é um jovem comerciante que teve de fugir após se opor a um grupo de "milicianos", a ponto mesmo de organizar uma oposição local contra a máfia. Ele foi preso e torturado, acusado de tráfico. Sua esposa foi estuprada enquanto ele estava na prisão, e eles acabaram perdendo seu primeiro bebê, pois sua esposa estava com algumas semanas de gravidez. Após tantas violências, o casal decidiu fugir. Na consulta, o relato da travessia ocupou um lugar central no discurso de Aziz: é o tempo-espaço onde se cristaliza a experiência do trauma. A fuga ocorreu em dois momentos, primeiro foram até à Índia, onde o casal viveu alguns meses. Depois se sentindo ainda ameaçado, Aziz decidiu contratar um "atravessador" para partirem ainda "mais longe". Em Mumbai, o casal embarcou em uma travessia, descrita pelo casal como "apocalíptica". Durante os primeiros meses na França, Aziz não conseguiu se assentar, ele conseguia apenas ver o caos causado pela ausência de sentido que caracterizou essa viagem, sem destino certo buscado ou ansiado. Nos diz: "a viagem durou semanas. Nós não sabíamos para onde íamos. Um dia nos disseram que tínhamos chegado. Era a França" ${ }^{\text {"5 }}$.

Essa forma de migração é vivida como perda, como uma forma de desterritorialização, como nos relatam Deleuze e Guattari (1980). Faremos uso do termo "exterritorialização", uma vez que não há uma nova inscrição num outro território: a saída do espaço político de origem é forçada, e a chegada no novo território de acolhida se faz sem qualquer identificação política e cultural. Essa migração é

5 A este propósito, ver Saglio-Yatzimirsky, Kalapani: le trauma de la traversée dans la migration des demandeurs d'asile tamouls du Sri Lanka? (no prelo). vivida sob a forma de uma "renúncia à identidade", uma espécie de disfarce do eu como tentativa de entrar na pele do refugiado. Quando Karan consegue organizar sua fuga do Sri Lanka, primeiro da prisão e depois do país, é graças ao apoio logístico e financeiro de pessoas influentes do país. Ele embarca em um avião que partirá para África, depois Hong Kong, para chegar à França. Sobre sua partida, Karan dirá "no aeroporto eu estava disfarçado de um jovem rico que faz uma viagem de turismo. A cabeça raspada, óculos de sol, um bom paletó. Eu carregava poucas coisas comigo, para que ninguém pudesse me reconhecer". Karan se exprime como se fosse outro, outra pessoa que deixava o Sri Lanka e que chegava finalmente à França, onde ele continua sem poder se reconhecer.

Se essa exterritorialização é vivida pelos migrantes requerentes de asilo logo nos primeiros meses quando chegam ao atendimento, é possível ainda vislumbrar uma elaboração psíquica dessa migração. No entanto, esse processo de elaboração entra em contradição com o procedimento jurídico-administrativo do refugiado, já que o pedido de asilo é um pedido de proteção após uma fuga forçada. Essa situação não se confunde com a de uma migração escolhida, elaborada pela esperança de melhores condições de vida e de futuro. Essa contradição acaba por manter o sujeito no tempo da perda e produz alienação. No trabalho clínico, observamos a consequência imediata desta alienação política, pois acaba impedindo a possibilidade de uma elaboração positiva da migração pelos sujeitos.

\section{A construção do "refugiado"}

Os pacientes que chegam como requerentes de asilo devem se inscrever em uma trajetória político-institucional. Neste sentido, sua inscrição em um serviço hospitalar é um ato para poderem ser reconhecidos como "refugiados", uma vítima de atos de violência. Deparamos com o paradoxo que comporta certa ameaça para a situação clínica e para o espaço terapêutico que funda o encontro entre o médico e o paciente. Efetivamente, para poderem ser atendidos no serviço hospitalar, é necessário que o trauma seja atestado desde o preenchimento da ficha de inscrição, pela entrevista preliminar ou pelo encaminhamento de outros médicos. O diagnóstico de estresse pós-traumático é extremamente importante para o procedimento jurídico -administrativo que cerca o paciente requerente de refúgio. Ticktin (2013) denuncia esta engrenagem paradoxal que captura os pacientes estrangeiros em busca de documentação com fins de tratamento médico6.

Para obterem esse estatuto, os sujeitos migrantes desenvolvem uma série de estratégias as quais colocam seu corpo como último recurso. Ticktin (2013) aponta para as

\footnotetext{
6 No site oficial da administração francesa, sobre o direito de permanência para tratamento médico (1998), podemos ler: "Se você está gravemente doente, poderá eventualmente ser autorizado a permanecer na França para se tratar. Vossa demanda será examinada segundo procedimento particular que deverá respeitar o segredo médico". Recuperado de, http:// vosdroits.service-public.fr/F17164.xhtml
} 
formas de manipulação do biológico e a mutilação do corpo que se deriva: um corpo que advém como valor mercadológico no mercado político da imigração. O médico sabe que esse diagnóstico é necessário para garantir o direito temporário do imigrante em estado de vulnerabilidade psíquica de permanecer no território para tratamento. Mas ele é também consciente que os fundamentos para a constituição do dossiê médico funcionam sempre do mesmo modo: se busca agravar o quadro do paciente para tentar impressionar os juízes. Paradoxalmente, logo que o sujeito adquire seus documentos para permanência no território, seu alívio é tão grande que, ao invés de possibilitar a abertura para o início de um verdadeiro trabalho psicoterápico, provoca a interrupção imediata do tratamento.

\section{A construção da "vítima" ou do "suspeito"}

A construção da "vítima do traumatismo" na economia moral das sociedades ocidentais produz como consequência a construção de um sujeito vitimado e uma participação concreta do Estado na proteção do migrante requerente de asilo quando este tem seu discurso reconhecido (Fassin \& Rehtman, 2007). Enquanto esse reconhecimento não é reconhecido, o requerente de asilo é tomado como "suspeito", tanto por sua situação de indocumentado quanto pelo estatuto de sua "suposta" história, já que ele poderia tê-la inventado, ou "falsificado". O contexto político e jurídico do requerente de asilo, na Europa e especificamente na França, não cessa de lhes imputar a sombra do migrante econômico.

A propósito dos requerentes de asilo na Grã-Bretanha e do sistema geral de "suspeito" que envolve tanto os imigrantes quanto as autoridades britânicas, Griffiths (2012) recusa a oposição simplista que opõe uma construção de um relato "verdadeiro" e de um relato "falso". De acordo com o autor, "em certas situações, mentir pode ser uma resposta racional face às categorias reducionistas que envolvem a imigração e a incapacidade burocrática de levar em conta a complexidade da situação. Esta incapacidade acaba por desencorajar a verdade e encorajar a produção de elementos falsos" (p. 10). Neste sentido, Ticktin (2013) faz uma análise sobre o posicionamento dos juízes da CNDA: o que buscam esses juízes que assistem a um desfile ininterrupto de sri-lankeses com a mesma história de tortura e crime, e que devem se submeter a uma política de cotas, selecionando apenas $10 \%$ dos requerentes de proteção? Sobre os elementos que entram em jogo na análise dos juízes, o autor destaca a presença de três elementos puramente subjetivos, construídos pela intuição e pela emoção levando em conta cada vez menos a análise racional dos dossiês: os juízes selecionam, primeiramente, "histórias plausíveis" ("legal narrative"), os casos originais ou "excepcionais", e, por fim, as consideradas "vítimas puras" (pp. 13-137).

Aziz e Karan experimentam o peso dessa suspeita quando passam na OFPRA e na CNDA. Aziz fica completamente desconcertado pelas questões que lhe são colocadas pelo juiz e que lhe parecem secundárias a sua história: detalhes sobre a festa nacional de seu país, sobre a geografia de sua região natal. Diante do estresse, do medo e da perda de memória, o julgamento de OFPRA se torna insuportável: "me disseram que eu não conhecia a história do meu país, logo pensaram que eu não era de Bangladesh. Vejam isso! Eu não sou de Bangladesh, não sou francês. Então, eu não sou nada?"

Quanto a Karan, ele teve de enfrentar a suspeita do tradutor, um compatriota que lhe diz: "vai, confessa, você vem da Inglaterra para achar trabalho aqui!" Todo edifício de certezas do sujeito desmorona quando seu sofrimento aparece aos olhos do outro como ilegítimo. Acabam sendo aprisionados entre aquilo que tem a dizer e aquilo que o outro, seu compatriota ou os advogados, espera que ele diga para parecer "crível" aos olhos do juiz.

\section{A consulta em psicoterapia: liberar o sujeito do seu desígnio}

Em nossas consultas, não tratamos com a forma de "relatório oficial" produzido sob forma de narrativa destinada às autoridades. Muitos pacientes nos trazem um exemplar em mãos e pedem ao psicólogo que leia o documento, o que este, geralmente, se abstém de fazer. Nosso esforço é de sair dessa narrativa para dar lugar à palavra singular do sujeito. Karan se recusa a ocupar e a falar do lugar ao qual é destinado no imaginário social: migrante, estrangeiro, requerente de asilo, vítima, suspeito.

\section{Reintroduzir o outro e a cultura}

O trauma depende não exclusivamente do acontecimento traumático, mas também de certo preparo psíquico do sujeito a metabolizar a efração traumática. Esta capacidade depende, entre outros, do recurso cultural do paciente, de sua capacidade de simbolizar seu lugar no mundo; por isso o atendimento no serviço de psicotraumatologia do Hospital Avicenne propõe um dispositivo que favorece a emergência dos elementos de cultura do paciente, no sentido de Winnicott (1965-2000), como um espaço criativo que permite a elaboração simbólica do paciente e uma possibilidade de uma ancoragem identitária.

A cena terapêutica integra a dimensão cultural do paciente no próprio dispositivo clínico e na formação dos terapeutas: estes terão uma origem diversificada, uma formação multiprofissional, uma prática clínica sensível à problemática transcultural. Esta diversidade cultural e de formação influencia diretamente a qualidade da escuta. Os profissionais do serviço reconhecem a herança legada pela etnopsiquiatria. A partir das reflexões de Devereux, uma das ideias diretrizes da prática clínica com migrantes é que a desordem psíquica e a doença têm um sentido específico na cultura do paciente. Trata-se do aspecto etiológico da investigação terapêutica. Quando aplicada à clínica do trauma, esta perspectiva etnopsicanalítica visa à liberação do núcleo enrijecido da significação, possibilitando a atribuição do sentido aos fatos psíquicos, graças à inclusão da 
história do sujeito em uma nova "matriz de interpretação" e à produção de um sistema associativo apoiado nas fontes culturais e nas "teorias etiológicas" fornecidas pelo paciente (Nathan, 1994, p. 281). As consultas têm o objetivo de colocar em movimento esse espaço cultural do paciente, a partir da elaboração de uma palavra engajada na língua do paciente: língua materna que carrega os elementos culturais do paciente e que possibilita o trabalho das associações significantes e da metaforização.

O Grupo trauma, no qual acolhemos o paciente, é uma forma de atendimento complementar ao acompanhamento individual. É composto por um coletivo de profissionais - psiquiatras, psicólogos, psicanalistas - que se organizam em torno do paciente com o objetivo inicial de dar suporte e acolhida (holding) ao sujeito. Graças ao seu modo de formação e de funcionamento, o grupo tem um valor performativo de reconstituição do coletivo para fazer emergir em seu centro a história do sujeito no trauma. Como mediador cultural, reativa o sentido do coletivo quebrado no sujeito enviado a sua solidão: solidão da perda e da separação; sentimento abissal na medida que o trauma confronta o sujeito à angustia. "O trauma individual desolidariza (isola o indivíduo dos outros membros do grupo) uma vez que é povoado de relatos impossíveis a compartilhar" (Cyrulnik, 2012, p. 189).

A articulação entre trauma e cultura acontece na medida em que o grupo terapêutico funciona graças às diferentes origens dos diversos terapeutas. Não apenas a passagem do trauma individual à posição de testemunha atribui sentido à experiência do trauma, religando-o a uma história. No trauma intencional, como apresentamos anteriormente, é precisamente a dimensão do outro, do desejo, da linguagem e da cultura que foram mutilados. Trata-se de fazer emergir novamente a dimensão da alteridade, graças à mediação da palavra.

\section{O risco de alienação do outro cultural}

Um dos princípios da antropologia médica é a importância de levarmos em conta o meio cultural do paciente para melhor compreendermos a expressão de seu sofrimento psíquico. A cultura nos fornece uma grade de inteligibilidade da doença. Em um segundo tempo, a etnopsicanálise propõe trabalhar diretamente com as referências culturais do paciente, por exemplo, pode inscrever o universo dos espíritos ou das divindades do paciente como interlocutores na consulta, ou ainda, pode passar prescrições mágico-religiosas para afastar o sofrimento.

Não iremos aqui nos aprofundar no debate já bastante documentado de crítica da etnopsiquiatria, apenas iremos apontar os riscos de mais uma forma de alienação que pode implicar essa teoria. O psicólogo, o psicanalista, ou psicoterapeuta, no dispositivo hospitalar, não é autorizado a se tomar por um curandeiro. Por um lado porque o terapeuta é capaz apenas de dominar parcialmente as referências culturais do paciente, por outro, sua posição não permite que se atribua certas funções de médico ou curandeiro tradicional, uma vez que o paciente buscou o recurso de um tratamento hospitalar ocidental e não de um representante religioso de sua comunidade de origem. Não respeitar essa indicação seria negar a subjetividade do sujeito migrante em sua adesão, ou não aos modelos ditos tradicionais (Rechtman, 2000).

Por fim, não respeitar essa indicação pode ainda produzir um efeito mais grave quando se trata do risco psíquico para o migrante, pois ao negar que houve desterritorialização, acaba-se por não conceber a capacidade do sujeito de propor uma nova ordem para sua relação simbólica com o mundo, diretamente relacionada a sua capacidade psíquica, a sua própria história e a suas estratégias pessoais. O risco da etnopsiquiatria na clínica com refugiados é justamente a reificação ou especialização da cultura do outro, a ponto de alienar o sujeito a uma cultura coisificada e de lhe recusar a possibilidade de separação desse lugar de alienação que o deslocamento geográfico pode favorecer na migração.

\section{Do silêncio mortífero ao silêncio sintomático e a resistência}

Quando Karan chega à consulta, se cala. Ou melhor, nos responde com um sorriso tímido que vai bem, mas logo se afunda em um silêncio profundo capaz de durar longos minutos. É assim que começam sempre suas consultas. Karan encontra-se preso aos fatos traumáticos que se apresentam a ele cruamente, não permitindo nenhuma forma de simbolização. Nossos primeiros encontros com Karan são marcados pela violência do trauma que o aprisiona. O paciente é capturado no silêncio, fruto de uma mortífera ausência de significantes que impede toda tentativa de reencontro com sua história.

Karan, progressivamente, retoma a palavra. Está habitado por imagens traumáticas e deverá transformar em relato todas as imagens da tortura; "achar as palavras" para partir ao reencontro do seu "ideal", àquele que lhe conduziu a se engajar na luta tâmil. Seu silêncio, seu esquecimento, aquilo que ele não consegue dizer, como a culpa que sente ao ter deixado dois de seus amigos na prisão, uma vez que ele acabou conseguindo sair. Seria esse o sentido da passagem entre o silêncio mortífero, siderante, do trauma e o silêncio sintomático, enlaçado com o regime do significante, que permite um início da elaboração da demanda, do qual nos apresenta Rosa (2012) e Cyrulnik (2012), ao afirmar que o silêncio emerge quando sabemos que o outro não poderá nos entender, ou seja, um emudecimento como forma de defesa e proteção.

Entretanto, outro tipo de silêncio aparece, uma espécie de silêncio definitivo como resposta aos juízes da CNDA. Não se trata do mesmo emudecimento traumático que pode aparecer no atendimento clínico. Esse silêncio se impõe em face da violência da taxonomia identificatória imposta a Karan, como migrante, refugiado, vítima ou suspeito, desde sua chegada ao território francês. Um silêncio que é forma de resistência, se fizermos nossos os termos de Devereux. Trata-se aqui de uma forma de renúncia da identificação imposta e uma defesa contra a dessubjetivação. Entendemos essa defesa não no sentido psicanalítico, 
ligada ao sintoma, mas sim como uma última forma de resistência. A resistência para Devereux (2009) teria uma dupla função, qual seja, de proteger a verdadeira identidade do sujeito, no próprio ato de escondê-la. Esta proposta supõe outra abordagem clínica do sujeito migrante: menos uma clínica fundada na interpretação dos mecanismos de defesa e dos sintomas do sujeito, e mais uma prática ancorada na escuta do sujeito que não se sentiria mais paralisado pelo discurso do outro que lhe transforma em objeto.

\section{A eloquência do sujeito da palavra}

Propomos construir uma clínica do trauma com os requerentes de refúgio, menos ancorada em torno do conceito de cultura (uma vez que anunciamos os riscos de reificação e de essencialização desta abordagem) e mais, sobre uma experiência singular que respeite a história de cada paciente. $O$ requerente de asilo padece de dupla alienação. O primeiro tipo de alienação é imposta por sua condição político-social, a qual um discurso jurídico - da legalidade, da prova - vem ameaçar a própria expressão discursiva do sujeito que requer o refúgio, que teve de fugir das violências no seu país e que foi levado a se excluir politicamente de sua comunidade cultural. O segundo tipo de alienação é produzida pelo tratamento terapêutico que faz pesar sobre o sujeito, sua identidade étnica e religiosa, como se sua origem pudesse explicar sua doença e orientar o tratamento. Trata-se, então, de descolar o sujeito de um discurso político que identifica o migrante requerente de asilo para lhe permitir recontar sua própria história, reconstituir seus laços sociais através de um trabalho de memória. A ideia é de permitir ao sujeito que foi confrontado à violência extrema do mal, do aterrorizante encontro com essa face oculta do humano, de se posicionar como sujeito do laço social e de sua história.

Diremos que o trabalho psicanalítico deverá ser repensado, pois no trauma, a dinâmica da associação livre entre significantes é interrompida. $\mathrm{O}$ trabalho psicanalítico deverá ser orientado pelo manejo da transferência e da contratransferência, o que irá contribuir para produção de efeitos de desidentificação do sujeito. Será necessário reativar, via palavra, o encontro inicial com o Outro da linguagem e do desejo: no espaço entre significantes que podem circular entre o paciente e o terapeuta. A cultura terá seu espaço, não como instância intrusiva, nem ameaçadora, mas sim como espaço significante para o jogo da linguagem, em uma "palavra que dialetiza" (Hassoun, 1994).

No caso de Aziz, que após sua travessia traumática não foi capaz de se inscrever em uma dinâmica de construção e de filiação, o terapeuta propõe analisar a organização de sua viagem tomando como ponto de partida os elementos de cultura trazidos pelo paciente destinados a garantir a proteção de sua família. Trata-se do baraka, da benção concedida por Allah que impediu o nascimento de um filho em um país que ele será obrigado a deixar. Teria sido inconcebível deixar a mulher, o filho. Sua esposa teria tido seu filho fora de sua casa materna, como preconizado pela tradição. A viagem de exílio teria sido muito dura para um bebê recém-nascido, e este teria certamente sucumbido às dificuldades. Allah, com a perda do bebê, teria visado à proteção da família para garantir ao casal o acesso a parentalidade dentro da tradição. Apenas a partir desta proposição de uma proteção de Allah, lançada pelo paciente, que ele poderá recomeçar sua história em uma terra que lhe é ainda estrangeira. A despeito da dificuldade de sua situação e da primeira recusa de seu pedido de refúgio pela OFPRA, Aziz se tornará pai alguns meses mais tarde e poderá receber seu filho em seus braços, cercando-o dos laços de amizade de sua comunidade.

Com Karan, o trabalho terapêutico irá consistir em reativar os laços desfeitos pelo trauma. Ele poderá reescrever duas vezes seu relatório administrativo para análise de seu pedido junto à OFPRA e a CNDA. Neste, ele propõe "contar sua história". Ao escrever sua história depois das consultas, ele começa a se sentir apoiado pelas palavras que fazem mediação e ordenam o espaço-temporal de sua história, inscrevendo-a em um destino coletivo da comunidade tâmil do Sri-Lanka. Durante esse trabalho, Karan pode alimentar o testemunho de sua própria história sem temer a clivagem entre o lá e o aqui, sem temer as imposições identitárias que lhe forçaram a deixar seu país e a silenciar.

Neste trabalho, visamos resituar o sujeito nas condições socio-históricas de sua enunciação e possibilitar a emergência dos significantes que poderão transformar o trauma em experiência compartilhada. Hassoun (1994) nos fala de uma "posição de testemunha" que irá permitir o migrante se situar no novo espaço, onde irá ocupar outro lugar na ordem simbólica, em que ao estar livre da alienação totalitária poderá se exprimir e se construir. A cultura aparecerá, aqui, como espaço simbólico que emerge graças à proposição de uma pluralidade de sentidos disponíveis ao sujeito para que se exprima e possa carregar seu sofrimento. Trata-se da ideia de cultura que faz a transmissão entre o passado e o futuro do refugiado, ou "exilado" nas palavras de Hassoun. Trata-se de uma cultura restaurada, persistente, que não se limita à expressão trágica dos acontecimentos históricos. Uma noção de cultura que estrutura o sujeito em suas primeiras identificações e referências, capaz de acolher toda sorte de heranças transmitidas pela migração. A elaboração desta clínica, livre de certa noção fixa de cultura, supõe levarmos em conta o contexto político do refugiado e permitir fazer falar o sujeito.

\section{From story to narrative, from alienation to subject: clinic with asylum seekers}

Abstract: In this article, we will aim to highlight the specificity and limits of a transcultural consultation in the Psychiatry Service of the Avicenne Hospital (France) with asylum seekers from Africa and South Asia affected by traumatic experiences that 
resulted in psychological disturbances. We will try to show that a clinical approach that takes into account the social and political context and the legal status of these "migrant" patients will allow the emergence of the word of the subject. Based on the construction of two case fragments, we will demonstrate how the political and social representations concerning the "migrant", "refugee", "victim", "suspect" leave their concrete and symbolic marks in the subject as well as influence the way the therapy is carried out. This will allow us, in a second step, to question the notion of alienation. Lastly, we will make a clinical proposition that aims to empty the clinical space from the constraints imposed by social representations that silence the subject.

Keywords: asylum seekers, subject, alienation, trauma, culture.

\section{Du récit à la parole, de l'aliénation au sujet: clinique en institution avec des demandeurs d'asile}

Résumé: Cet article interroge les spécificités et les limites de la consultation de psycho-traumatologie du service de psychiatrie de l'hôpital Avicenne avec des demandeurs d'asile originaires principalement d'Asie du Sud et d'Afrique. Seul un abordage clinique qui prend en compte la particularité du contexte socio-politique et de la situation juridique des patients peut permettre au sujet de faire entendre sa parole. A partir de deux cas cliniques, nous montrerons comment les représentations qui entourent le sujet, successivement catégorisé comme migrant, réfugiés, victime ou suspect, ont un impact concret et symbolique sur le patient et sur la dynamique clinique. A partir de ce constat, nous interrogerons la notion d'aliénation. Dans un troisième temps, nous ferons des propositions cliniques afin de dégager l'espace clinique des impositions aliénantes qui imposent le silence au sujet.

Mots-clés: demandeurs d'asile, sujet, aliénation, trauma, culture.

\section{Del relato a la palabra, de la alienación a lo sujeto: la experiencia de una práctica clínica con los refugiados en una institución de salud}

Resumen: En este artículo, se destaca la especificidad y los límites de un servicio de consulta de psiquiatría transcultural en el Servicio de Psiquiatría del Hospital Avicena (Francia) con los solicitantes de refugio, originarios principalmente de África y Asia del Sur, y que buscan atención psicológica por presentaren trastornos psicotraumáticos. Se trata de demostrar que un enfoque clínico que tiene en cuenta el contexto socio-político y la situación jurídica de los pacientes 'migrantes' permitirá la reaparición de la palabra al sujeto. Desde la construcción de dos fragmentos clínicos, tratamos de mostrar cómo las representaciones políticas y sociales del «migrante», «refugiado», «víctima», «sospechoso» dejan sus marcas concretas y simbólicas en los sujetos así como influyen en nuestra forma de conducir el trabajo clínico. Esto nos permitirá, en un segundo momento, cuestionar la noción de alienación. Por último, vamos a lanzar una proposición clínica que tiene como objetivo eliminar de la consulta en psicoterapia las limitaciones impuestas por las representaciones sociales que callan a los hombres.

Palabras clave: solicitantes de asilo, sujeto, alienación, trauma, cultura.

\section{Referências}

Bokanowski, T. (2002). Traumatisme, traumatique, trauma. Revue française de psychanalyse, 66(3).

Cyrulnik, B. (2012). Sauve-toi, la vie t'appelle. Paris: Odile Jacob.

Deleuze, M., \& Guattari, F. (1980). Capitalisme et schizophrénie (tome 2: mille-plateaux). Paris: Minuit.

Devereux, G. (2009). La renonciation à l'identité, défense contre l'anéantissement. Paris: Payot.

Fassin, D., \& Rechtman, R. (2007). L'Empire $d u$ traumatisme, enquête sur la condition de victime. Paris: Flammarion.

Ferenczi, S. (1934-1982). Réflexions sur le traumatisme. In Cuvres complètes, IV (1927-1933, pp. 139-147). Paris: Payot.

Griffiths, M. (2012, october). Vile liars and truth disorders. Anthropology Today, 28(5), 8-12.
Halluin Mabillot, E. d'. (2012). Les épreuves de l'asile. Associations et réfugiés face aux politiques du soupçon. Paris: EHESS.

Hassoun, J. (2011). Les contrebandiers de la mémoire. Toulouse: Eres.

Hochman, J. (2001). Intersubjectivité, empathie et narration. In Qu'est ce qui guérit dans la psychothérapie? Paris: PUF.

Irago, D. (2011). Le demandeur d'asile aux prises avec le dehors et le dedans. Cliniques, 2.

Lachal, C., Ouss-Ryngaert, L., Moro, M.-R. (2003). Comprendre et soigner le trauma en situation humanitaire. Paris: Dunod.

Mijolla-Mellor, S. (2011). La mort donnée. Essai de psychanalyse sur le meurtre et la guerre. Paris: PUF. 
Nathan, T. (1994). L'influence qui guérit. Paris: Odile Jacob.

Rechtman, R. (2000, mai-juin.). De la psychiatrie des migrants au culturalisme des ethnopsychiatries. Hommes et Migrations, 1225, 46-61.

Ricoeur, P. (1990). Soi-même comme un autre. Paris: Seuil.

Rosa, M. D., Carignato, T., Berta, S. (2007). Metáforas do deslocamento: migrantes, imigrantes e refugiados e a condição errante do desejo. In A. Costa, \& D. Rinaldi (Org.), Escrita e psicanálise. Rio de Janeiro, RJ: Companhia de Freud.

Rosa, M. D. (2012, maio). Migrantes, imigrantes e refugiados: a clínica do traumático. Revista de Cultura e Extensão, 7, 67-78.

Rousseau, C., Said, M. T., Gagné, M.-J., \& Bibeau, G. (1998). Between myth and madness: the premigration dream of leaving among young somali refugees. Culture, Medicine and Psychiatry, 22(4), 385-411.

Saglio-Yatzimirsky, M.-C. (no prelo). Kalapani: le trauma de la traversée dans la migration des demandeurs d'asile tamouls du Sri Lanka? Hommes et Migrations.
Semprún, J. (1994). L'Écriture ou la vie. Paris: Gallimard.

Sironi, F. (1999). Bourreaux et victimes. Psychologie de la torture. Paris: Odile Jacob.

Ticktin, M. (2013). Casualties of care. Berkeley, CA: University of California Press.

Vacchiano, F. (2013). A la recherche d'une citoyenneté globale. Le mouvement comme subjectivité dans l'expérience des mineurs migrants isolés en Europe. In Conférence DU de psychiatrie transculturelle, Université Paris 13, Paris.

Winnicott, D. W. (1965-2000). Le concept de traumatisme par rapport au développement de l'individu au sein de la famille. In La crainte de l'effondrement et autres situations cliniques (pp. 292-312). Paris: Gallimard.

Zaltzman, N. (Dir.). (1999). La résistance de l'humain. Paris: PUF.

Zaltzman, N. (2007). L'Esprit du mal. Paris: L'Olivier.

Recebido: 22/04/2014

Revisado: 09/07/2014

Aceito: 09/09/2015 